\title{
Thermal expansion coefficient determination of polylactic acid using digital image correlation
}

\author{
Adrian - Ioan Botean ${ }^{1, *}$ \\ ${ }^{1}$ Mechanical Engineering Department, Mechanical Faculty, Technical University of Cluj - Napoca, Romania
}

\begin{abstract}
This paper aims determining the linear thermal expansion coefficient (CTE) of polylactic acid (PLA) using an optical method for measuring deformations called digital image correlation method (DIC). Because PLA is often used in making many pieces with 3D printing technology, it is opportune to know this coefficient to obtain a higher degree of precision in the construction of parts and to monitor deformations when these parts are subjected to a thermal gradient. Are used two PLA discs with 20 and $40 \%$ degree of filling. In parallel with this approach was determined the linear thermal expansion coefficient (CTE) for the copper cylinder on the surface of which are placed the two discs of PLA.
\end{abstract}

\section{Introduction}

In this study we aim to determine the linear thermal expansion coefficient (CTE) [1] of the polylactic acid (PLA) using the digital image correlation method.

Polylactic acid (PLA) is a thermoplastic material made from renewable resources such as corn starch or sugar cane. It is biodegradable and difficult to recycle. PLA does not present hazardous components and is considered compatible with the environment. PLA can come into contact with food and is a non-toxic thermoplastic material. [2], [3]

It is a strong and rigid material, making it more complicated to use for parts that require joining. PLA is used as a matrix for some fiber - reinforced composites that are $100 \%$ biodegradable. [4] Polylactic acid is currently used in the biomedical field, from which various elemens such as stents are made.

Depending on the molecular weight and degree of crystallinity, polylactic acid can be used in various applications. For example, if biaxially oriented the material can maintain its stability to $130-150{ }^{\circ} \mathrm{C}$. It also has very good optical properties, with excellent machinability and excellent behaviour both at twisting and bending. [4]

The material can be configured to provide different mechanical properties depending on the chosen technological processing. This process can be by injection, molding, foil extrusion, blowing, or firing using the best known manufacturing methods and equipment. [4]

The advantage of polylactic acid is the low temperature 3D printing capability.

The 3D printer is defined as a mechanism thet makes physical objects using input file information obtained through a three - dimensional graphics software, such as
SolidWorks. [5] Through 3D printing, mechanism with a fully functional role can be created from just one technological process, without the need for other post production assembly methods.

Fused Deposition Modeling (FDM) - extrusion medeling is the most widely used manufacturing technology because of its simplicity and affordability (Fig.1). [6]

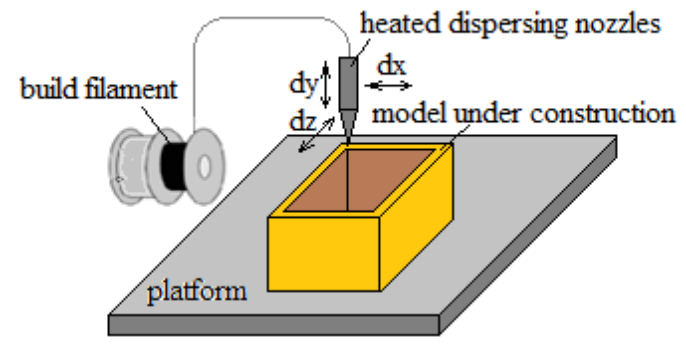

Fig. 1. Extrusion modeling.

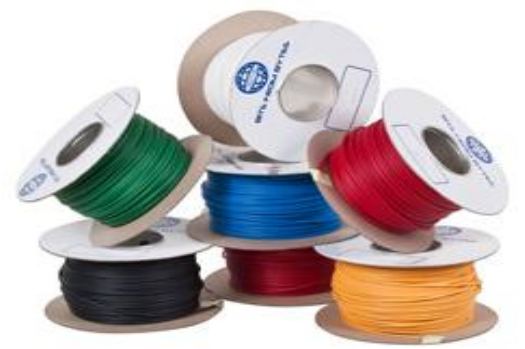

Fig. 2. Filament made from PLA (polylactic acid).

This method is used in modeling, prototyping, but also in production applications. It works with a software application where the 3D model is sliced, in the first phase, in cross - sectioned sections called layers. The printing process is carried out by passing a PLA filament (Fig.2) through an extruder that heats it to the melting point, after which the layer is applied uniformly over the layer until the 3D model conforms to the CAD file. [6] The head or extruder is heated to melt the filament made

* Corresponding author: boteanadrianioan@yahoo.com 
from PLA. It moves both horizontally and vertically under the action of a numerical control mechanism. It is controlled directly by the CAM printer application. In motion, the extruder dposits a thin plastic string that, by cooling, sticks to the previous layer so that the shape of the desired pattern is created. [7]

With the help of the digital image correlation method (DIC), it is possible to characterize, in real time, the coefficient of linear thermal expansion (CTE) of PLA. It can be a reliable tool for measuring thermal deformations, especially for plastics material with a high CTE. [7], [8]

\section{Experimental part}

Materials and methods. To determinate CTE for PLA two disks werw made using the 3D CREATR printer based on the Fused Deposition Modeling (FDM) method. The first disk has a filling degree of $20 \%$ $(\mathrm{d}=29.8[\mathrm{~mm}], \mathrm{h}=3.118[\mathrm{~mm}])$ and the second disk has a filling degree of $40 \%(\mathrm{~d}=29.2[\mathrm{~mm}], \mathrm{h}=2.952[\mathrm{~mm}])$, according to Fig.3.

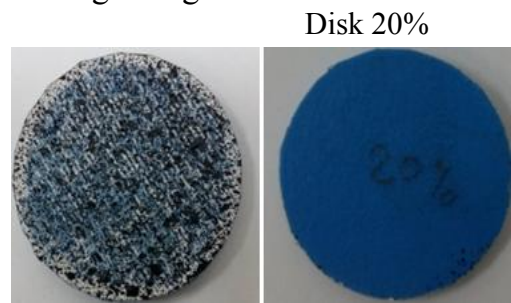

Disk $40 \%$

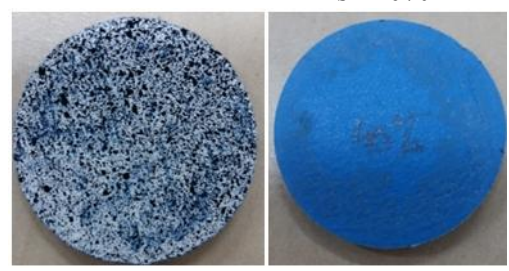

Fig. 3. Disks made of PLA.

The experimental installation is shown in Fig.4 and consists of the following elements: the disk made of PLA which is placed on the copper cylinder which is heated by a Mark VII (MG VISHAI) soldering station. The temperature of the cylinder is monitored using a Pt100 type heat - resistant, connected to the Spider 8 data acquisition system (HBM) and the data is viewed, in real time, using the CatmanEasy software (HBM) according to Fig.5. [9], [10] PLA disk temperature is monitored, in real time, using a T400 (FLIR) thermal imaging camera, as shown in Fig.6. The $\Delta$ h expansion of the PLA disk in the transverse plane is measured with the Q400 digital correlation system from Dantec Dynamics (www.dantecdynamics.com), that includes two CCD cameras, 1/8", 1624×1234 pixel resolution, frame rate up to $30 \mathrm{~Hz}$, control electronic, lenses with 17 $\mathrm{mm}$ focal length and patented cold light system HILIS
(High Intensity LED Illumination System) for very homogenous illumination of the specimen. [7], [11]

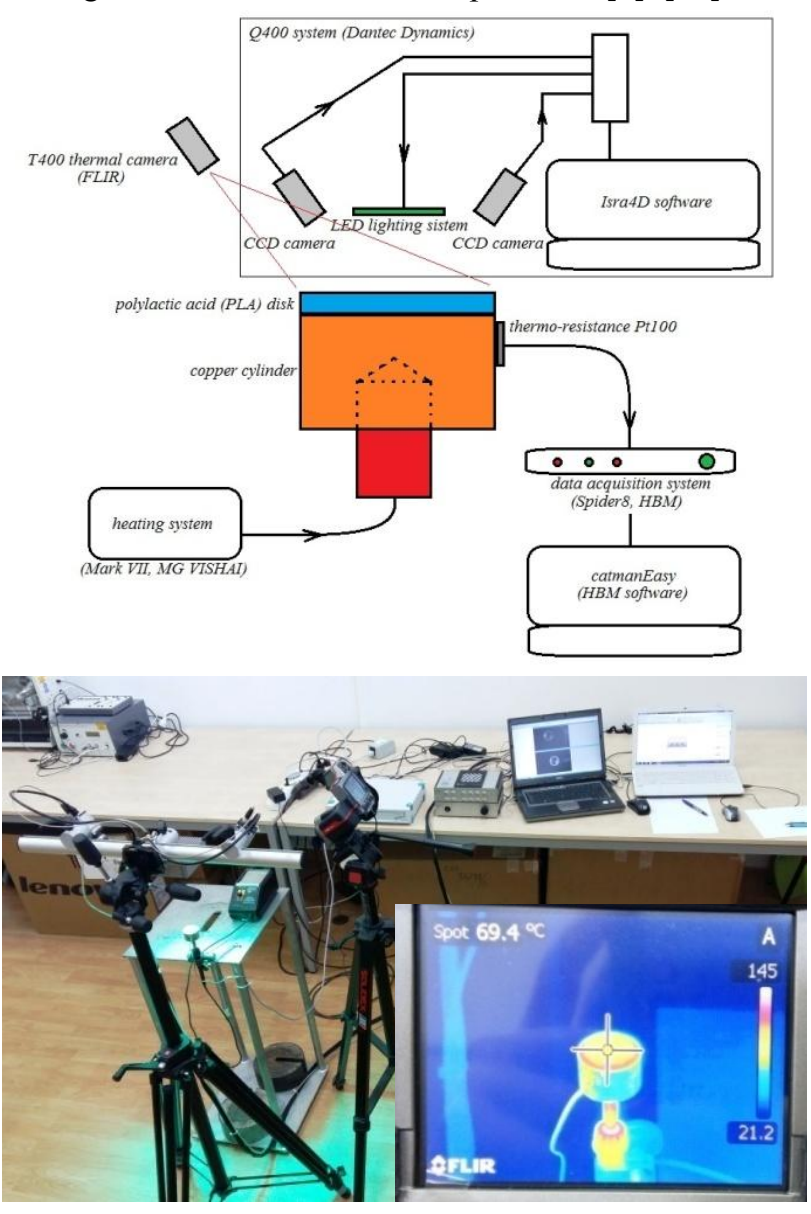

Fig. 4. The experimental installation.

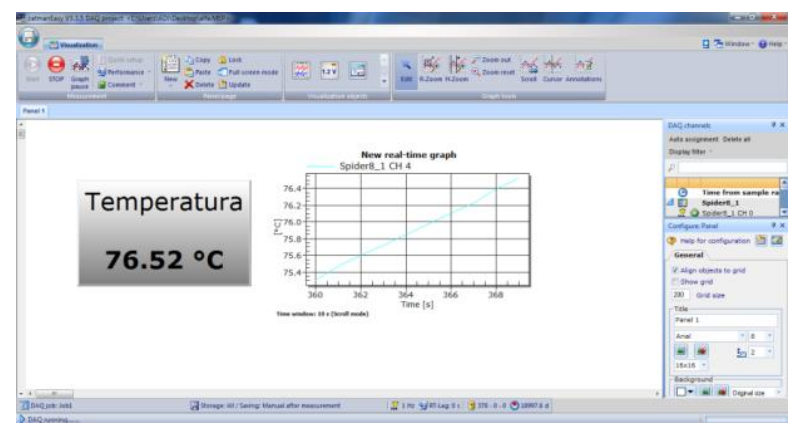

Fig. 5. Real - time monitoring of cylinder temperature with CatmanEasy, Spider8 and Pt100.

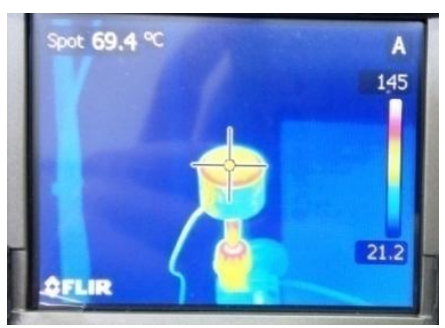

Fig. 6. Real - time monitoring of PLA disk with T400 thermal imaging camera. 
Within the Q400 digital image correlation system, intrinsec parameters are determined by lens focal length, lens principal point, and radial and tangential lens distortion. To determine the intrinsec parameters, a calibration plate (Fig.7) is used, which is rotated and translated manually in front of the CCD cameras. The Isra4D software automatically records the nodal points of the calibration plate in a sequence of images and calculates intrinsec and extrinsec parameters.

Thus, the intrinsec CCD camera 1 parameters are: focal length $(x ; y) 3820 \pm 30 ; 3800 \pm 30$, principal point (x; y) $610 \pm 20 ; 441 \pm 14$, radial distortion $\left(\mathrm{r}^{2} ; \mathrm{r}^{4}\right)-0.14 \pm 0.03$; $5.9 \pm 1.6$, tangential distorsion $\left(\mathrm{t}_{\mathrm{x}} ; \mathrm{t}_{\mathrm{y}}\right)-0.0023 \pm 0.0009$; $0.002 \pm 0.002$ and for CCD camera 2 are: focal length ( $x$; y) $3830 \pm 30 ; 3810 \pm 30$, principal point $(\mathrm{x} ;$ y) $700 \pm 40$; $453 \pm 18$, radial distortion $\left(r^{2} ; r^{4}\right)-0.26 \pm 0.03 ;-1.4 \pm 0.9$, tangential distorsion $\quad\left(\mathrm{t}_{\mathrm{x}} ; \quad \mathrm{t}_{\mathrm{y}}\right) \quad-0.0012 \pm 0.0013$; $\quad$ $0.003 \pm 0.002$.

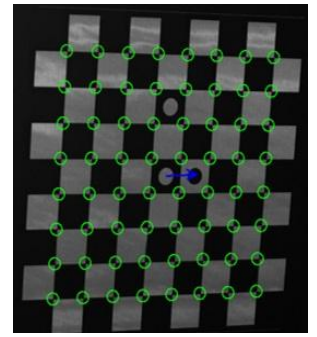

Fig. 7. Determining the intrinsec and extrinsec parameters of CCD cameras using the calibration plate.

Extrinsec parameters are represented by the translation vector and the rotation matrix. Thus, the extrinsec parameters for $\mathrm{CCD}$ camera 1 are: rotation vector $(\mathrm{x} ; \mathrm{y} ; \mathrm{z})-3.020 \pm 0.004 ;-0.0679 \pm 0.0016$; $0.769 \pm 0.008$, translation vector $(\mathrm{x} ; \mathrm{y} ; \mathrm{z}) 5 \pm 2 ; 1.9 \pm 1.2$; $323 \pm 3$ and for CCD camera 2 are: rotation vector $(\mathrm{x} ; \mathrm{y}$; z) $-3.029 \pm 0.004 ;-0.014 \pm 0.002 ;-0.810 \pm 0.013$, translation vector $(\mathrm{x} ; \mathrm{y} ; \mathrm{z})-4 \pm 3 ; 11.6 \pm 1.6 ; 340 \pm 3$.

In parallel with the determination of the deformations of the PLA disk in the transverse plane, the deformations of the copper cylinder (having a diameter $\mathrm{d}=37.51[\mathrm{~mm}]$ and a height $\mathrm{h}=24.9[\mathrm{~mm}]$ ) will be measured according to Fig.8.

Once the displacement $\Delta \mathrm{h}$ are determined, depending on the temperature gradient $\Delta \mathrm{t}$ the CTE can be determined by the following relation:

$$
\alpha=\frac{\Delta h}{h \cdot \Delta t}\left[\frac{m m}{m m \cdot{ }^{\circ} \mathrm{C}}\right]
$$

For each disk (20\% and $40 \%$ filling degree) or cylinder, three sets of measurements carried out were generally noted with Set1, Set2 and Set3. Parallel to the study of the CTE for PLA disks, the same coefficient will be obtained for the copper cylinder, which is the support and heating element of the disks.
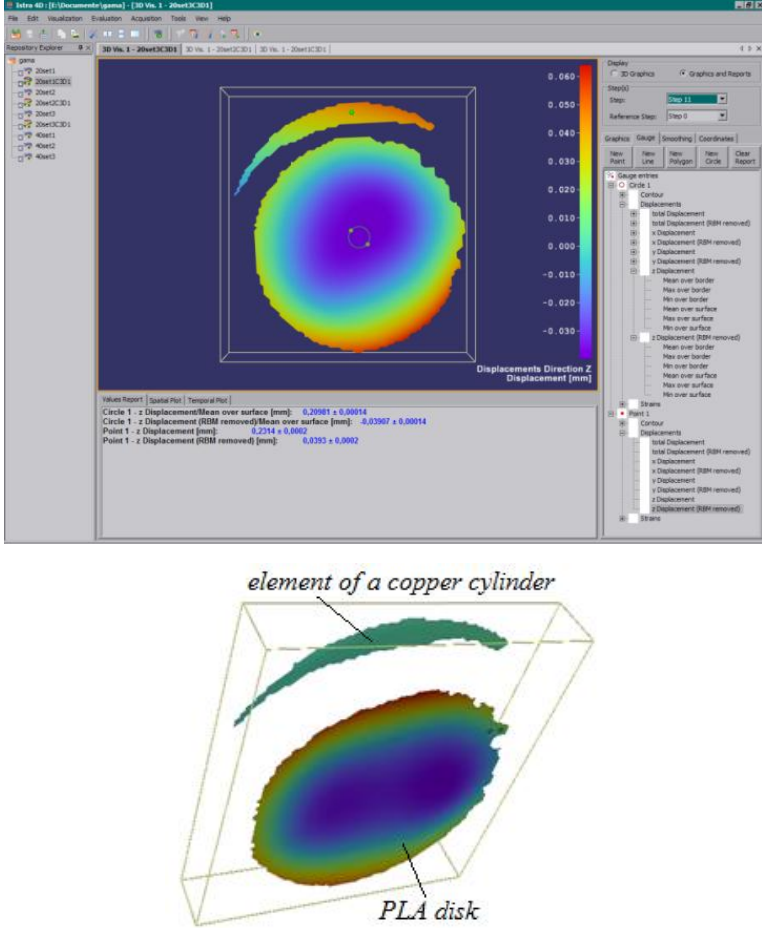

Fig. 8. Determination of the displacement in the transverse plane of the PLA disk and of the copper cylinder with the aid of digital image correlation method.

\section{Results}

In Fig.9 is plotted the temperature variation diagram of the PLA disk with $20 \%$ degree of filling according to time monitored with the thermal imaging camera T400 and in Fig.10 is plotted the temperature variation of the copper cylinder, according to time, monitored with Pt100 thermoresistor transducer.

In Fig. 11 is plotted the temperature variation diagram of the PLA disk with $20 \%$ degree of filling according to time monitored with the thermal imaging camera T400 and in Fig. 12 is plotted the temperature variation of the copper cylinder, according to time, monitored with Pt100 thermoresistor transducer.

In Fig. 13 is plotted of the deformation $\Delta \mathrm{h}$ in the transverse plane for the PLA disk with $20 \%$ degree of filling according to the temperature gradient $\Delta t$ monitored with the thermal imaging camera T400 and Fig.14 shows the variation of the deformation diagram $\Delta \mathrm{h}$ in the transverse plane for the copper cylinder according to the temperature gradient $\Delta \mathrm{t}$ monitored by the Pt thermoresistor transducer.

In Fig. 15 is plotted of the deformation $\Delta \mathrm{h}$ in the transverse plane for the PLA disk with $40 \%$ degree of filling according to the temperature gradient $\Delta \mathrm{t}$ monitored with the thermal imaging camera T400 and Fig. 16 shows the variation of the deformation diagram $\Delta \mathrm{h}$ in the transverse plane for the copper cylinder according to the temperature gradient $\Delta \mathrm{t}$ monitored by the Pt100 thermoresistor transducer. 


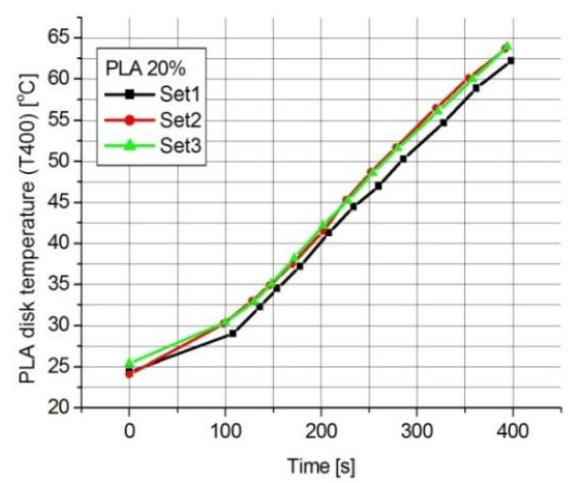

Fig. 9. $\Delta \mathrm{t}\left[{ }^{\circ} \mathrm{C}\right]$ vs $\Delta \mathrm{t}[\mathrm{s}]$ for PLA disk (20\%).

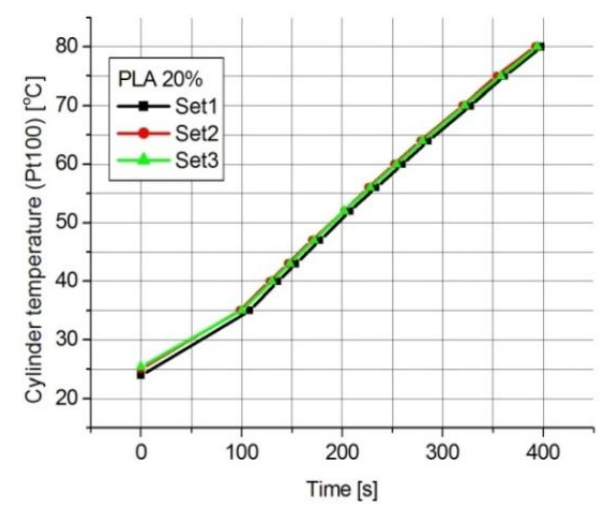

Fig. 10. $\Delta \mathrm{t}\left[{ }^{\circ} \mathrm{C}\right]$ vs $\Delta \mathrm{t}[\mathrm{s}]$ for copper cylinder.

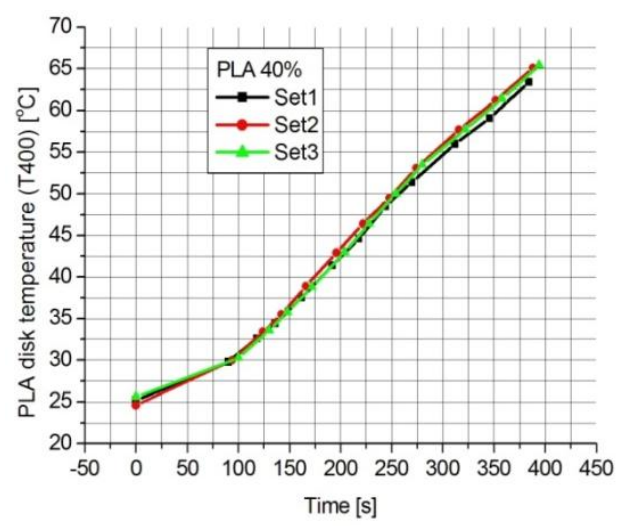

Fig. 11. $\Delta \mathrm{t}\left[{ }^{\circ} \mathrm{C}\right]$ vs $\Delta \mathrm{t}[\mathrm{s}]$ for PLA disk (40\%).

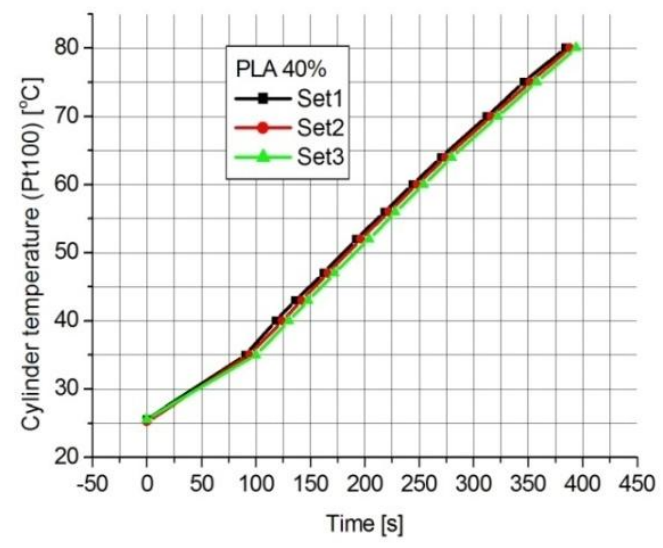

Fig. 12. $\Delta \mathrm{t}\left[{ }^{\circ} \mathrm{C}\right]$ vs $\Delta \mathrm{t}[\mathrm{s}]$ for copper cylinder.

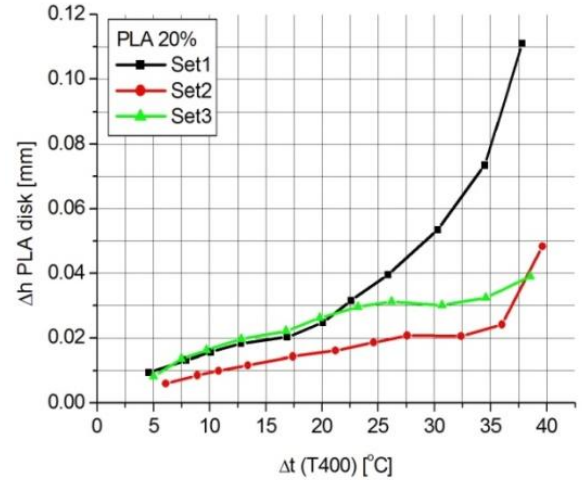

Fig. 13. $\Delta \mathrm{h}[\mathrm{mm}]$ vs $\Delta \mathrm{t}\left[{ }^{\circ} \mathrm{C}\right]$ for PLA disk (20\%).

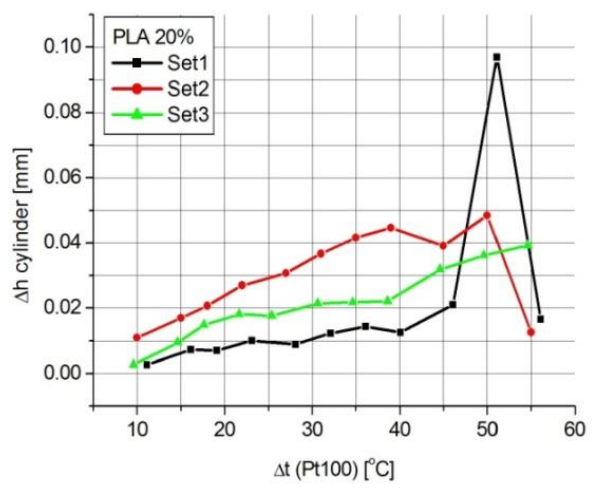

Fig. 14. $\Delta \mathrm{h}[\mathrm{mm}]$ vs $\Delta \mathrm{t}\left[{ }^{\circ} \mathrm{C}\right]$ for copper cylinder.

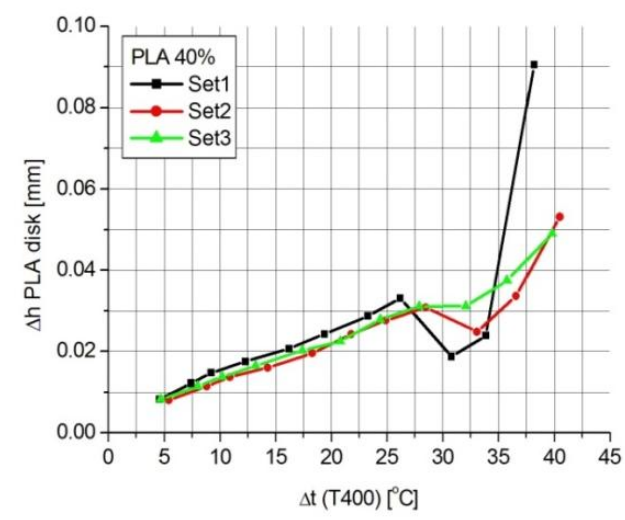

Fig. 15. $\Delta \mathrm{h}[\mathrm{mm}]$ vs $\Delta \mathrm{t}\left[{ }^{\circ} \mathrm{C}\right]$ for PLA disk $(40 \%)$.

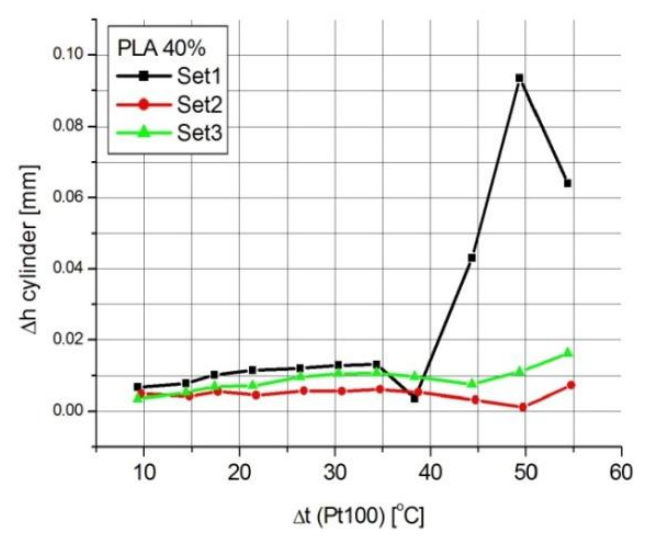

Fig. 16. $\Delta \mathrm{h}[\mathrm{mm}]$ vs $\Delta \mathrm{t}\left[{ }^{\circ} \mathrm{C}\right]$ for copper cylinder. 
Fig. 17 shows the variation diagram of the CTE for the PLA disk having $20 \%$ degree of filling according to the temperature gradient $\Delta \mathrm{t}$ and Fig.18 shows the variation diagram of the CTE for the cooper cylinder according to the temperature gradient $\Delta \mathrm{t}$.

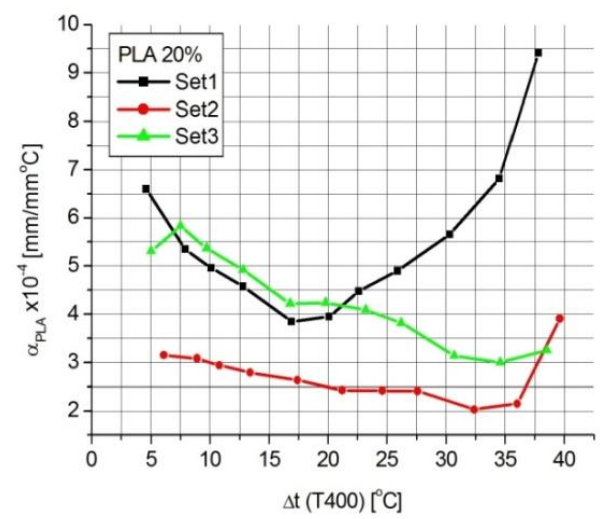

Fig. 17. $\alpha\left[\mathrm{mm} / \mathrm{mm} \cdot{ }^{\circ} \mathrm{C}\right]$ vs $\Delta \mathrm{t}\left[{ }^{\circ} \mathrm{C}\right]$ for PLA disk (20\%).

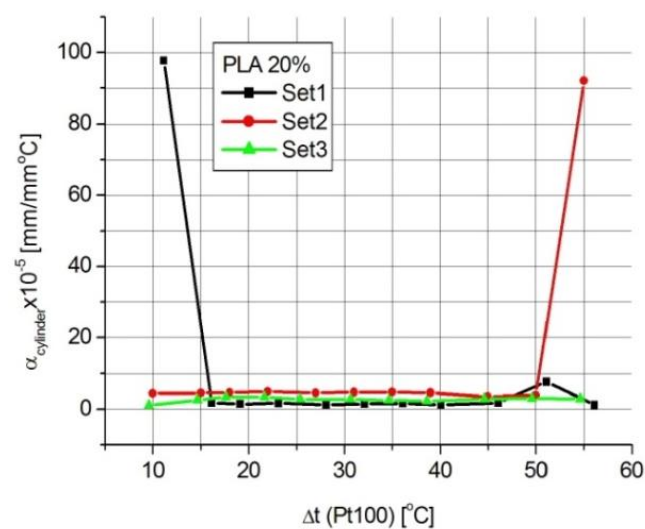

Fig. 18. $\alpha\left[\mathrm{mm} / \mathrm{mm} \cdot{ }^{\circ} \mathrm{C}\right]$ vs $\Delta \mathrm{t}\left[{ }^{\circ} \mathrm{C}\right]$ for copper cylinder.

Fig.19 shows the variation diagram of the CTE for the PLA disk having $40 \%$ degree of filling according to the temperature gradient $\Delta \mathrm{t}$ and Fig.20 shows the variation diagram of the $\mathrm{CTE}$ for the cooper cylinder according to the temperature gradient $\Delta \mathrm{t}$.

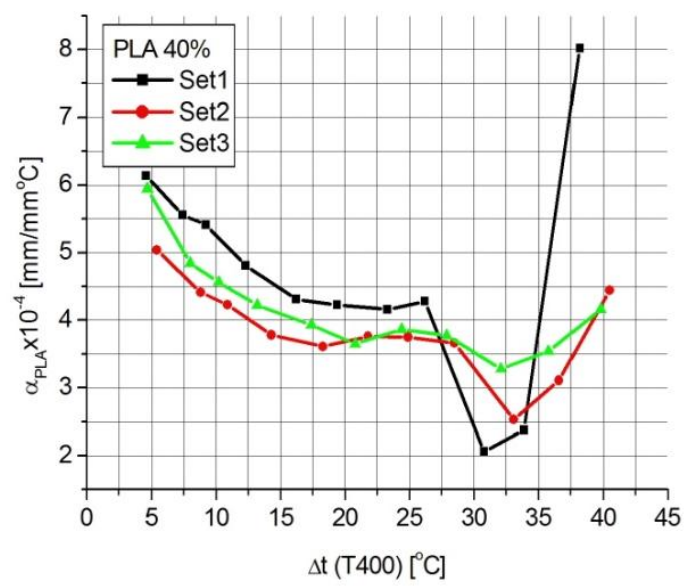

Fig. 19. $\alpha\left[\mathrm{mm} / \mathrm{mm} \cdot{ }^{\circ} \mathrm{C}\right]$ vs $\Delta \mathrm{t}\left[{ }^{\circ} \mathrm{C}\right]$ for PLA disk $(40 \%)$.

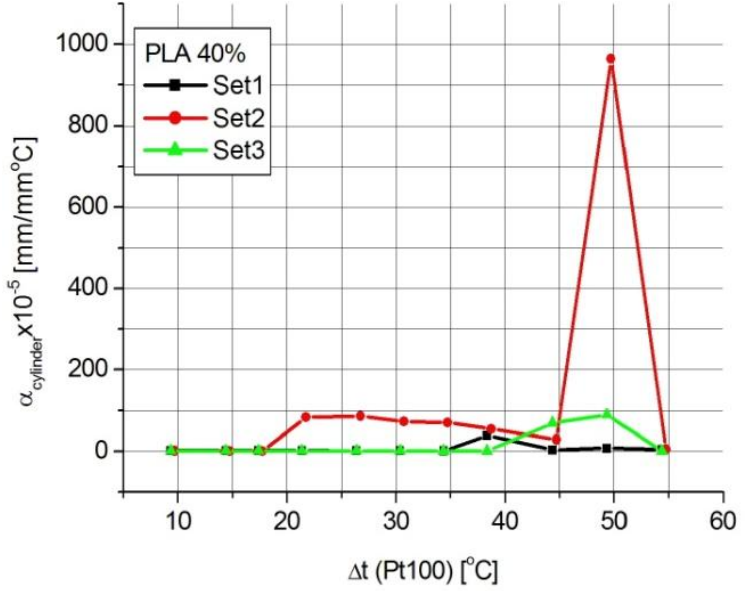

Fig. 20. $\alpha\left[\mathrm{mm} / \mathrm{mm} \cdot{ }^{\circ} \mathrm{C}\right]$ vs $\Delta \mathrm{t}\left[{ }^{\circ} \mathrm{C}\right]$ for copper cylinder.

In Fig.21 is drawn the average line of the six curves representing the CTE for PLA as well as the representation of the linear function for this. In Fig.22 is drawn the average line of the six curves representing the CTE for copper as well as the representation of the linear function for this.

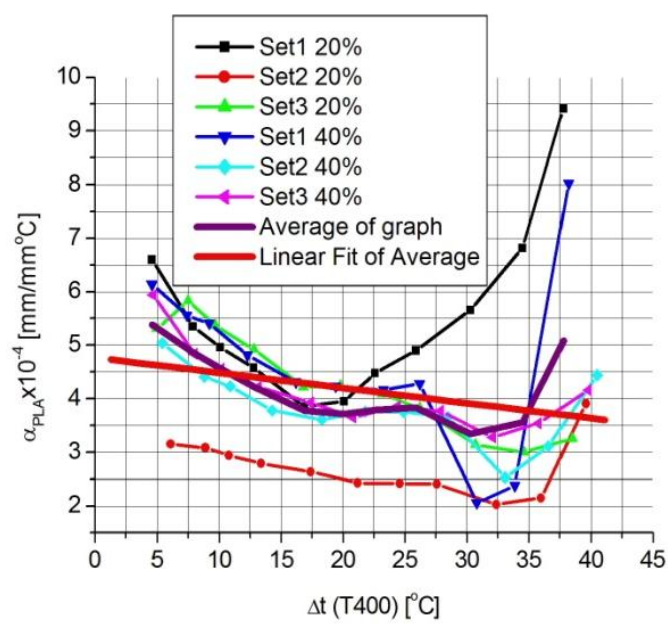

Fig. 21. $\alpha\left[\mathrm{mm} / \mathrm{mm} \cdot{ }^{\circ} \mathrm{C}\right]$ vs $\Delta \mathrm{t}\left[{ }^{\circ} \mathrm{C}\right]$ for PLA disk $(40 \%)$.

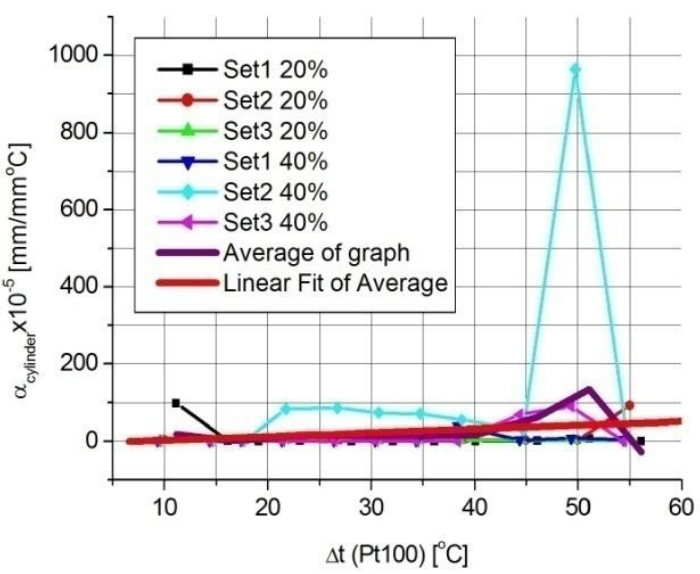

Fig. 22. $\alpha\left[\mathrm{mm} / \mathrm{mm} \cdot{ }^{\circ} \mathrm{C}\right]$ vs $\Delta \mathrm{t}\left[{ }^{\circ} \mathrm{C}\right]$ for copper cylinder. 
From the analysis of the obtained results and the diagrams drawn in the present paper, the following observations can be made:

For the PLA disk with $20 \%$ degree of filling the CTE has the following mean values: for Set1 $\alpha_{\mathrm{PLA}}=4.29 \cdot 10^{-4}$ $\left[\mathrm{mm} / \mathrm{mm} \cdot{ }^{\circ} \mathrm{C}\right]$, for Set $2 \alpha_{\mathrm{PLA}}=2.74 \cdot 10^{-4}\left[\mathrm{~mm} / \mathrm{mm} \cdot{ }^{\circ} \mathrm{C}\right]$, for Set3 $\alpha_{\mathrm{PLA}}=5.5 \cdot 10^{-4}\left[\mathrm{~mm} / \mathrm{mm} \cdot{ }^{\circ} \mathrm{C}\right]$. The mean value is $\alpha_{\text {PLA }}=4.17 \cdot 10^{-4}\left[\mathrm{~mm} / \mathrm{mm} \cdot{ }^{\circ} \mathrm{C}\right]$.

For the PLA disk with $40 \%$ degree of filling the CTE has the following mean values: for Set1 $\alpha_{\mathrm{PLA}}=4.15 \cdot 10^{-4}$ $\left[\mathrm{mm} / \mathrm{mm} \cdot{ }^{\circ} \mathrm{C}\right]$, for Set $2 \alpha_{\mathrm{PLA}}=3.84 \cdot 10^{-4}\left[\mathrm{~mm} / \mathrm{mm} \cdot{ }^{\circ} \mathrm{C}\right]$, for Set3 $\alpha_{\mathrm{PLA}}=4.66 \cdot 10^{-4}\left[\mathrm{~mm} / \mathrm{mm} \cdot{ }^{\circ} \mathrm{C}\right]$. The mean value is $\alpha_{\text {PLA }}=4.55 \cdot 10^{-4}\left[\mathrm{~mm} / \mathrm{mm} \cdot{ }^{\circ} \mathrm{C}\right]$.

The average CTE for the two disks is $\alpha_{\mathrm{mPLA}}=4.36 \cdot 10^{-4}$ $\left[\mathrm{mm} / \mathrm{mm} \cdot{ }^{\circ} \mathrm{C}\right]$.

Comparing this result with those reported in the literature $\left([3] \alpha_{\mathrm{PLA}}=0.7 \cdot 10^{-4}\left[1 /{ }^{\circ} \mathrm{C}\right] ;[12] \alpha_{\mathrm{PLA}}=0.85 \cdot 10^{-4}\right.$ $\left.\left[1 /{ }^{\circ} \mathrm{C}\right] ;[13],[14],[15] \quad \alpha_{\mathrm{PLA}}=7.4 \cdot 10^{-4}\left[1 /{ }^{\circ} \mathrm{C}\right]\right)$ a good concordance can be observed.

For the copper cylinder, when the PLA disk with a $20 \%$ degree of filling is placed on it, the CTE has the following mean values: for Set1 $\alpha_{\mathrm{Cu}}=2.69 \cdot 10^{-5}$ $\left[\mathrm{mm} / \mathrm{mm} \cdot{ }^{\circ} \mathrm{C}\right]$, for Set $2 \alpha_{\mathrm{Cu}}=4.458 \cdot 10^{-5}\left[\mathrm{~mm} / \mathrm{mm} \cdot{ }^{\circ} \mathrm{C}\right]$, for Set3 $\alpha_{\mathrm{Cu}}=1.52 \cdot 10^{-5}\left[\mathrm{~mm} / \mathrm{mm} \cdot{ }^{\circ} \mathrm{C}\right]$. The mean value is $\alpha_{\mathrm{Cu}}=2.88 \cdot 10^{-5}\left[\mathrm{~mm} / \mathrm{mm} \cdot{ }^{\circ} \mathrm{C}\right]$.

For the copper cylinder, when the PLA disk with a $40 \%$ degree of filling is placed on it, the CTE has the following mean values: for Set1 $\alpha_{\mathrm{Cu}}=1.35 \cdot 10^{-5}$ $\left[\mathrm{mm} / \mathrm{mm} \cdot{ }^{\circ} \mathrm{C}\right]$, for Set $2 \alpha_{\mathrm{Cu}}=1.33 \cdot 10^{-5}\left[\mathrm{~mm} / \mathrm{mm} \cdot{ }^{\circ} \mathrm{C}\right]$, for Set3 $\alpha_{\mathrm{Cu}}=2.2 \cdot 10^{-5}\left[\mathrm{~mm} / \mathrm{mm} \cdot{ }^{\circ} \mathrm{C}\right]$. The mean value is $\alpha_{\mathrm{Cu}}=1.62 \cdot 10^{-5}\left[\mathrm{~mm} / \mathrm{mm} \cdot{ }^{\circ} \mathrm{C}\right]$.

The average CTE for copper cylinder is $\alpha_{\mathrm{mCu}}=2.25 \cdot 10^{-5}\left[\mathrm{~mm} / \mathrm{mm} \cdot{ }^{\circ} \mathrm{C}\right]$.

Comparing this result with those reported in the literature $\left([16] \alpha_{\mathrm{Cu}}=(1.01-1.661) \cdot 10^{-5}\left[1 /{ }^{\circ} \mathrm{C}\right]\right.$; [17], [18] $\left.\alpha_{\mathrm{Cu}}=2.2 \cdot 10^{-4}\left[1 /{ }^{\circ} \mathrm{C}\right]\right)$ a good concordance can be observed with the indication that the maximum and minimum values were taken into account from the results obtained after the measurements.

\section{Conclusions}

The present study describes how to determine CTE using a non - contact optical method, namely the 3D - DIC technique. This allows real - time and full - field analysis of the object to determine displacements and strain depending on a temperature gradient.

Although the displacements in the transverse plane of the two disks made of PLA and the copper cylinder are very low, the $3 \mathrm{D}-\mathrm{DIC}$ method is of good accuracy provided that a few disturbing factors (vibrates, shocks, etc.) are avoided.

In this case, the digital image correlation method is also shown to be a good tool for evaluating the linear thermal expansion coefficient in a very short time span.

\section{Acknowledgements}

This study was made possible by the technical support given by $\mathrm{PhD}$. Eng. Fechete Lucian, lecturer at the Automotive Engineering and Transportations
Department, Faculty of Mechanics, Technical University of Cluj-Napoca.

\section{References}

1. *** Vishay Micro-Measurements, Measurement of thermalexpansion characteristics of metals using strain gauges, Technical note tn-513-1, Retrieved from www.vishaymg.com (2007)

2. http://ro.wikipedia.org/wiki/Acid-polilactic

3. L.T. Lim, Auras, R., Rubino, M., Processing technologies for poly (lactic acid), Progress in Polymer Science, Volume 33, Issue 8, Pages 820-852 (2008)

4. http://www.icechim - pd.ro/ro/modif/modificare _biopolact_prezentare.html

5. http://despretot.info/wp-content/uploads /2012/08/ Imprimanta-3d- functionare.png

6. http://www.zspotmedia.ro/blog/printare-3d/

7. M.C. Dudescu, A.I. Botean, M. Hardau, Thermal expansion coefficient determination of polymeric materials using digital image correlation, Revista Materiale plastice, MPLAAM 50(1) (1-68), ISSN 0025/5289, Vol. 50, nr. 1, pag. 55-59, Bucureşti (2013)

8. P. Bing, X. Hui-Min, H. Tao, A. Asundi, Measurement of coefficient of thermal expansion of films using digital image correlation method, Polymer Testing, vol. 28, p.75-83 (2009)

9. K. Hoffmann, An introduction to measurements using strain gages, Hottinger Baldwin Messtechnik GmbH, Darmstadt (1989)

10. ***Spider8, Operating manual, Retrieved from www.hbm.com

11. C. Herbst, K. Splitthof, Q400 Application Note - TQ-400-Basics-3DCORR-002a-EN, Dantec Dynamics $\mathrm{GmbH}$, Germany, Retrieved from: www.dantecdynamics.com (2006)

12. https://omnexus.specialchem.com/polymer properties / properties/coefficient-of-linear-thermalexpansion

13. https://unprinter.wordpress.com/2013/10/07/thermalexpansion-in-polylactic-acid/

14. F. Gao, Advances in Polymer Nanocomposites, $1^{\text {st }}$ Edition (2012)

15. A.K. Mohanty, M. Misra, L.T. Drzal, Natural Fibers, Biopolymers, and Biocomposites, CRC Press (2005)

16. G.K. White, Thermal expansion of reference materials: copper, silica and silicon, J. Phys. D: Appl. Phys., vol.6, no.17 (1973)

17. K.G. Budinski, M.K. Budinski, Engineering Materials. Properties and Selection, Ninth Edition, Pearson

18. E. Avallone, T. Baumeister, A. Sadegh, Marks' Standard Handbook for Mechanical Engineers, $11^{\text {th }}$ Edition 